\title{
Exosomal transfer of miR-15b-3p enhances tumorigenesis and malignant transformation through the DYNLT1/ Caspase-3/Caspase-9 signaling pathway in gastric cancer
}

Shuchun Wei ${ }^{\dagger}$, Lei Peng ${ }^{\dagger}$, Jiajia Yang ${ }^{\dagger}$, Huaiming Sang, Duochen Jin, Xuan Li, Meihong Chen, Weifeng Zhang, Yini Dang* and Guoxin Zhang*

\begin{abstract}
Background: Exosomes are essential for tumor growth, metastasis, and are used as novel signaling molecules in targeted therapies. Therefore, exosomal miRNAs can be used in new diagnostic and therapeutic approaches due to their involvement in the development of cancers. However, the detailed biological function, potential molecular mechanism and clinical application of exo-miR-15b-3p in gastric cancer (GC) remains unclear.

Methods: miR-15b-3p mRNA levels in tissues, serum, cells and exosomes were analyzed using qRT-PCR assays. qRT$P C R$, immunohistochemical and western blotting analyses were utilized for the determination of DYNLT1 expression. The interrelationship connecting miR-15b-3p with DYNLT1 was verified using Dual-luciferase report, western blotting and qRT-PCR assays. Fluorescent PKH-26 or GFP-Lv-CD63 labeled exosomes, as well as Cy3-miR$15 b-3 p$, were utilized to determine the efficacy of the transfer of exo-miR-15b-3p between BGC-823 and recipient cells. Several in vitro assays and xenograft tumor models were conducted to determine exo-miR-15b-3p impact on GC progression.

Results: This is the first study to confirm high miR-15b-3p expression in GC cell lines, tissues and serum. Exosomes obtained from 108 GC patient serum samples and GC cell-conditioned medium were found to show upregulation of exo-miR-15b-3p, with the area under the ROC curve (AUC) being 0.820 [0.763-0.876], which is superior to the AUC of tissues and serum miR-15b-3p (0.674 [0.600-0.748] and 0.642 [0.499-0.786], respectively). In addition, high exo-miR-15b-3p expression in serum was found to accurately predict worse overall survival. SGC-7901 and GES-1 cells are capable of internalizing BGC-823 cell-derived exosomes, allowing the transfer of miR-15b-3p. Migration, invasion, proliferation and inhibition of apoptosis in vitro and in vivo were enhanced by exo-miR-15b-3p, by restraining DYNLT1, Cleaved Caspase-9 and Caspase-3 expression.
\end{abstract}

Conclusions: This study identified a previously unknown regulatory pathway, exo-miR-15b-3p/DYNLT1/Caspase-3/ Caspase-9, which promotes GC development and GES-1 cell malignant transformation. Therefore, serum exo-miR15b-3p may be a potential GC diagnosis and prognosis biomarker, which can be used in precise targeted GC therapy.

Keywords: Exosomes, miR-15b-3p, Gastric cancer, DYNLT1, Apoptosis, Cleaved Caspase-3, Cleaved Caspase-9

\footnotetext{
*Correspondence: yeani_hi@126.com; guoxinz@njmu.edu.cn

${ }^{+}$Shuchun Wei, Lei Peng and Jiajia Yang contributed equally to this work. Department of Gastroenterology, The First Affiliated Hospital of Nanjing Medical University, Nanjing 210029, China
}

(c) The Author(s). 2020 Open Access This article is distributed under the terms of the Creative Commons Attribution 4.0 International License (http://creativecommons.org/licenses/by/4.0/), which permits unrestricted use, distribution, and reproduction in any medium, provided you give appropriate credit to the original author(s) and the source, provide a link to the Creative Commons license, and indicate if changes were made. The Creative Commons Public Domain Dedication waiver (http://creativecommons.org/publicdomain/zero/1.0/) applies to the data made available in this article, unless otherwise stated. 


\section{Introduction}

Worldwide, gastric cancer (GC) frequency is fourth highest among malignancies and the second most-likely cause of cancer-related death [1], as well as the second most frequent cancer in China [2]. Although, GC diagnosis, as well as treatment methods have improved greatly during recent times, the GC patient five-year survival rate is reported to be $10-30 \%$, due to diagnosis delays $[1,3]$. GC development and progression are regulated by a variety of factors, such as genetics, epigenetics and the environment $[4,5]$. Due to its high complexity, current treatment methods, including surgery, chemotherapy, and radiotherapy, are not yet able to achieve satisfactory therapeutic outcomes [6]. Therefore, identifying sensitive and specific biomarkers for GC diagnosis and identifying GC progression related molecular mechanisms are critical for early diagnosis and effective targeted therapy of GC.

As small non-coding RNAs, microRNAs (miRNAs) can function as vital posttranscriptional mRNA translation and gene expression regulators in most cell types [7]. miRNAs are found in serum and other body fluids, and function as biomarkers of diseases due to their differential expression between patients and healthy individuals [8]. Exosomes are extracellular vesicles with an average diameter of $30-200 \mathrm{~nm}$ that have the same topology as the cell and contain a specific composition of proteins, lipids, nucleic acids and glycoconjugates [9]. They are derived from endocytic membranes and serve as vehicles for cell-to-cell communication, remodeling the extracellular environment or transmitting signals and molecules to neighboring recipient cells $[9,10]$. Due to their potential use in numerous pathological and physiological processes of various diseases, differences in exosome function between healthy and diseased individuals has attracted much attention from researchers [911]. Interestingly, exosomes can carry numerous miRNAs that act locally or enter into circulation to act at distal sites, since internal miRNAs are protected from being digested by RNase, as a result of the protection offered by the lipid membrane of the exosomes [12, 13]. New evidence has demonstrated that exosomal miRNAs (exo-miRNAs) transmitted between cells perform a crucial regulatory function in apoptosis, invasion, migration, proliferation, as well as chemoresistance of multifarious tumors, including GC [13-17].

The correlation between miR-15b-3p and GC development has not been demonstrated in any previous study. In this current study, exosomal miR-15b-3p (exo-miR15b-3p) was found to be released by BGC-823 cells, promoting GC progression and the malignant transformation of GES-1 (normal gastric mucosa epithelium cells), by regulating the DYNLT1/Caspase-3/Caspase- 9 axis. Additionally, the potential use of serum exo-miR-15b-3p for the diagnosis and prognosis of GC in the form of a liquid biological marker was also demonstrated. Thus, this study provides a novel target and perspective for GC diagnosis and prognosis through effective targeted therapies.

\section{Materials and methods \\ Specimens of a clinical nature}

Histologically confirmed GC tissue and paired adjacent noncancerous tissue were obtained from 108 patients undergoing surgical procedures at Nanjing Medical University's First Affiliated Hospital in China. The 108 patients mentioned above, were gender, age and disease history matched with 108 non-GC volunteers, who provided human serum samples. All clinical specimens were collected under the guidance of the Health Insurance Portability and Accountability Act (HIPAA) protocol and were stored at $-80^{\circ} \mathrm{C}$ after being frozen in liquid nitrogen, once collected. First Affiliated Hospital of Nanjing Medical University Ethics Committee Approval was obtained to conduct this study, while written consent was obtained from all participants.

\section{Cell culture}

The following three GC cell lines: normal GES-1 gastric mucosa epithelium cell line; moderately differentiated adenocarcinoma SGC-7901 cell line and the poorly differentiated adenocarcinoma BGC-823 cell line, were purchased from the Cell Bank of Type Culture Collection of the Chinese Academy of Sciences. The cells were cultured at $37^{\circ} \mathrm{C}$, in RPMI 1640 medium supplemented with $1 \%$ penicillin/streptomycin, $10 \%$ fetal bovine serum (FBS) and $5 \% \mathrm{CO}_{2}$. All culture medium reagents were obtained from Gibco, USA.

\section{Isolation and characterization of exosomes}

After the cells had reached a confluency of $70-80 \%$, the medium was changed to a RPMI 1640 medium with $10 \%$ exosome-depleted FBS (obtained through ultracentrifugation at $120,000 \times \mathrm{g}$ at $4{ }^{\circ} \mathrm{C}$ for $6 \mathrm{~h}$ [18]). After $48 \mathrm{~h}, 50$ $\mathrm{ml}$ of the conditioned medium (CM) was collected from each cell line, and ultracentrifugation was used to extract exosomes from the medium, following previously described standard procedures [19]. In order to collect blood samples for serum exosome isolation, ethylenediaminetetraacetic acid (EDTA) containing collection tubes were used. Within an hour, the tubes were centrifuged at $1900 \times \mathrm{g}$ at $4{ }^{\circ} \mathrm{C}$ for $10 \mathrm{~min}$, using a swinging bucket rotor. A new tube was used to collect the upper (yellow) serum phase, and $16,000 \times$ g centrifugation at $4{ }^{\circ} \mathrm{C}$ for $10 \mathrm{~min}$ was conducted to eliminate additional cellular fragments, as well as cell debris. Then, an exoEasy Maxi Kit (Qiagen, Hilden, Germany; Cat. Number: 76064) was used, as instructed by the manufacturer, 
to isolate serum exosomes. As described in a previous study [20], a FEI Tecnai T20 transmission electron microscope (TEM) (FEI Company, USA) was used to observe the exosomes, while a Nano Sight NS 300 system (Nano Sight Technology, Malvern, UK) was used to determine exosome quantity and size.

\section{Extraction of RNA and quantitative reverse transcription (qRT)-PCR assays}

TRIzol reagent (Invitrogen, USA) was used to extract total RNA from tissues, cells and CM derived-exosomes, which were purified using a miRNeasy Serum/Plasma Kit (Qiagen, Germany; Cat. Number: 217184), as instructed by the manufacturer. In addition, exosomal RNA was isolated directly from serum, using an exoRNeasy Serum/Plasma MidiKit (Qiagen, Hilden, Germany; Cat. Number: 77044). The miRNeasy Serum/Plasma Spike-In Control (cel-miR-39, Qiagen, Hilden, Germany; Cat. Number: 219610) was used as the serum miRNA expression profiling internal control, as instructed by the manufacturer. The cDNA of the RNAs were created with the aid of a PrimeScript ${ }^{\mathrm{Tm}}$ RT Reagent Kit (TaKaRa, Japan; Code No. RR037A (miRNAs)/RR036A (mRNAs)). TB Green ${ }^{\ominus}$ Premix Ex Taq ${ }^{\mathrm{TM}}$ (TaKaRa, Japan, Code No. RR420A) was used to conduct the qRT -PCR, with the results recorded using ABI StepOne ${ }^{\mathrm{Tm}}$ Software v2.3 (Applied Biosystems, USA). GAPDH functioned as an internal control for DYNLT1 mRNA levels and the relative miR-15b-3p expression of serum-exosomes were normalized to cel-miR-39, which was normalized to U6 in CM-exosomes, cells and tissues. The $2^{-\Delta C T}$ formula was used to determine gene expression fold change. Additional file 7: Table S1 lists all primary sequences used.

\section{Oligonucleotide transfection}

Lipofectamine2000 Reagent (Invitrogen, USA) and OptiMEM (Gibco, USA) were used, as instructed by the manufacturer, in 6-well plates to transfect the GenePharma Corporation (SGC, China) synthesized miR-15b$3 \mathrm{p}$ mimics/scrambled negative control RNA (NC) or miR-15b-3p inhibitor/scrambled negative control RNA (inhibitor-NC) into cells. After $48 \mathrm{~h}$ and $24 \mathrm{~h}$ of oligonucleotide transfection, cells were harvested to isolate total cell lysates and total RNA for western blotting and qRT-PCR analyses, in order to determine DYNLT1 and miR-15b-3p levels, respectively. The miR15b-3p mimics and inhibitor sequences mentioned above are listed in Additional file 7: Table S2.

\section{Lentivirus infection}

Genechem Inc. (China) constructed luciferase-labelled lentivirus vectors carrying miR-15b-3p (Lv-miR-15b-3p)/ negative control (Lv-NC), miR-15b-3p inhibitor (Lv- inhibitor)/negative control (Lv-inNC) and GFP-labelled lentivirus vectors containing CD63 (GFP-Lv-CD63) were used. BGC-823 cells were infected in 6-well plates, using $10 \mu \mathrm{l}$ of the aforementioned lentiviral vectors for 3 days at $37{ }^{\circ} \mathrm{C}$. Then, selection of successful lentiviral transfected cells was done using $1.0 \mu \mathrm{g} / \mathrm{ml}$ puromycin (Sigma Aldrich, USA). The primers used for the amplification of miR-15b-3p were: $5^{\prime}$-.

AGGTATGCACGCGTGAATTGTTACTTTTTTTTC TATAAAGCTAGGTTGG - 3' (sense) and 5'-GCCGA CACGGGTTAGGATCAAAAAACACTACGCCAATATT TA-CGTGC-3' (antisense). Sequences used for the Lv-miR15b-3p inhibitor were: 5'-AATTCAAAAACGAATCAT TATTTGCTGCTCTA-3' (sense) and 5'-CCGGTAGAG CAGCAAATAATGATTCGTTTTTG-3'(antisense). qRTPCR was performed to validate infection efficiency.

\section{Proliferation assay}

Into 6-well plates, the harvested cells were added at a concentration of $1 \times 10^{3}$ cells/well, for 10-15 days, to be used for the colony formation assay. Fixation of the colonies were done using $2 \mathrm{ml}$ of paraformaldehyde for 30 min, while $0.1 \%$ crystal violet was used for $30 \mathrm{~min}$ at room temperature for cell staining. In addition, a CellLight EdU Apollo567 In Vitro Kit (RiboBio, China) and a Cell Counting Kit-8 (CCK-8) kit (Dojindo Laboratories, Japan) were utilized to evaluate the proliferation of the cells. For the CCK- 8 assay, into each well of a 96well plate containing $2 \times 10^{3}$ transfected cells, $10 \mu \mathrm{L}$ of CCK-8 reagent was added at the same time every day for further incubation $(2 \mathrm{~h})$. A Microplate reader (ELX800; Bio-Tek, USA) was used to measure absorption at $450 \mathrm{~nm}$, at a series of time points $(0,24,36,48,72$ and $96 \mathrm{~h})$. For the 5-ethynyl-2'-deoxyuridine (EdU) assay, rigorous processing was carried out on the cells in 96well plates with the cells at a concentration of $2 \times 10^{4}$ cells/well, as instructed by the manufacturer [21]. Finally, a Nikon ECLIPSE E800 fluorescence microscope was used to examine the cell samples.

\section{Apoptosis assay}

An Annexin V-PI apoptosis detection kit (Vazyme Biotech Co. Ltd., China) was used in a manner similar to that of a previous description $[22,23]$ to detect apoptosis. Thereafter, fluorescence-activated cell sorting (FACS) was utilized to count the stained cells using CellQuest software (BD Biosciences, USA) connected to a Calibur flow cytometer. A TUNEL FITC Apoptosis Detection Kit (Vazyme Biotech Co. Ltd., China) was used, as instructed by the manufacturer, to conduct TUNEL staining. Immunofluorescence was observed using a Nikon ECLIPSE E800 fluorescence microscope. 


\section{Transwell assay}

First, into a 24-well plate, transwell assay inserts (Millipore, USA) were added. A Matrigel-coated membrane (50 $\mu \mathrm{L} /$ well, BD Biosciences, Franklin Lakes, NJ) was used for the invasion assay, while a normal membrane was used for the migration assay, as the apical chamber membrane. Then, $600 \mu \mathrm{L}$ of $10 \%$ FBS containing medium was seeded into the basolateral chamber, and $100 \mu \mathrm{L}$ of FBS-free RPMI 1640 medium (Gibco, USA) was added into the apical chamber containing $2 \times 10^{5}$ cells in each well to re-suspend the cells. After incubation for $24 \mathrm{~h}$ at $37^{\circ} \mathrm{C}$, PBS was used to rinse the Transwell plates twice, fix with $4 \%$ paraformaldehyde for 30 min, while $0.1 \%$ crystal was used for $30 \mathrm{~min}$ at room temperature, for staining. Subsequently, utilizing an inverted light microscope the cells were observed, photographed and counted.

\section{Luciferase reporter assay}

The pmirGLO dual-luciferase miRNA target expression vector (Promega, USA) was transfected with the PCR amplified 3' untranslated regions (3'-UTR) of DYNLT1 mRNA. In 24-well plates, the luciferase construct containing wild-type (WT) or mutated binding site of DYNLT1 (constructed by Genechem Inc., China) were transfected into target cells. This was followed by cotransfection with miR-15b-3p mimics, inhibitor, NC or inhibitor-NC using Lipofectamine2000, to identify the binding site between DYNLT1 and miR-15b-3p. Determination of luciferase activity after $48 \mathrm{~h}$ of transfection and normalization with Renilla luciferase was done utilizing a Dual-Luciferase Reporter System Kit (E1910, Promega, USA), as previously reported [24].

\section{Western blotting analysis}

Protein extraction from cells, tissues, and exosomes were performed using a radioimmunoprecipitation assay (RIPA) kit (Sigma-Aldrich, USA), as instructed by the manufacturer. After determination of protein concentration using a bicinchoninic acid (BCA) kit (Pierce, USA), SDS-containing polyacrylamide gel (SDS-PAGE) was used for the separation of equal amounts $(35 \mu \mathrm{g}$ for cells and tissues, and $10 \mu \mathrm{g}$ for exosome pellets) of protein samples. Thereafter, the samples were moved onto polyvinylidene difluoride (PVDF) membranes (Bio-Rad, USA). Then, for $1 \mathrm{~h}, 5 \%$ non-fat milk in TBSTween (TBST) (0.1 M, pH 7.4) was used to block the membranes, followed by hybridization with primary antibodies against CD9 (ab92726, 1:1000 dilution), CD63 (ab217345, 1:1000 dilution), DYNLT1 (ab202583, 1:2000 dilution), BAX (ab32503, 1:1000 dilution), BCL-2 (ab32124, 1:1000 dilution) and TSG101 (ab125011, 1: 1000 dilution), from Abcam (USA); Cleaved caspase-3 (9664, 1:1000 dilution) and Cleaved caspase-9 (7237, 1:
1000 dilution), from Cell Signaling Technology (USA), overnight at $4{ }^{\circ} \mathrm{C}$. The antibodies for GAPDH (QYA03819B, 1:2000 dilution) and $\beta$-Actin (sc-47,778, 1: 1000 dilution) from Santa Cruz Biotechnology (USA) served as reference proteins. The immunocomplexes were incubated with corresponding horseradish peroxidase conjugated secondary antibodies (Applygen, China; 1:2000 dilution), for $2 \mathrm{~h}$ at room temperature. Thereafter, an enhanced chemiluminescence assay was conducted on a SuperSignal ${ }^{\mathrm{m}}$ West Femto Maximum Sensitivity Substrate $(34,095$, Thermo Fisher, USA) to visualize the blots.

\section{Exosome labeling and uptake}

The cells cultured on four-well chamber slides were washed with PBS thrice, fixed using 4\% paraformaldehyde for $15 \mathrm{~min}$, once again washed with PBS, and permeabilized using 0.5\% Triton-X 100 (dissolved in PBS) for $20 \mathrm{~min}$. For exosome tracking, exosomes secreted by the BGC-823 cells were labeled using PKH26 red fluorescent dye (Sigma-Aldrich, USA) or exosomal marker, CD63 (green; Genechem Inc., China), while Factin was stained using phalloidin-FITC (green), and DAPI (blue) was used to label nuclei. Cy3-(miR-15b-3p inhibitor/inhibitor- $\mathrm{NC} / \mathrm{mimics} / \mathrm{NC}$ ) were synthesized, as well as purified by RiboBio Co. (China). A Nikon ECLIPSE E800 fluorescence microscope was used to capture images. The uptake capacity of SGC-7901 and GES-1 into exosomes containing different miRNA sequences (mimics/NC/inhibitor/inhibitor-NC) was determined using immunofluorescence assays and qRT-PCR.

\section{Animal studies}

6-8 week old BALB/c-nu male nude mice were kept in an animal facility that was pathogen-free and were randomly divided into five groups $(n=5)$. The groups received subcutaneous injections of miR-15b-3p enriched/ Lv-NC exosomes, miR-15b-3p inhibited/Lv-inNC exosomes $\left(1 \times 10^{9}\right.$ exosomes $\left./ \mathrm{ml}\right)$ or PBS treated SGC-7901 cells $\left(2 \times 10^{6}\right.$ cells in $200 \mu \mathrm{l}$ PBS). The anesthetization of the mice was done using xylazine $(10 \mathrm{mg} / \mathrm{kg})$ or ketamine $(100 \mathrm{mg} / \mathrm{kg})$, while bioluminescence signals were observed using an IVIS 100 Imaging System (Xenogen, USA) $15 \mathrm{~min}$ after D-luciferin $(100 \mathrm{mg} / \mathrm{kg}$, Xenogen, USA) was injected into the mice. Once in 4 days, a digital caliper was used to measure the tumors and the following formula was used to calculate tumor volume: (width ${ }^{2} \times$ length) $/ 2$, until euthanasia, 28 days after cell inoculation. Finally, the subcutaneous tumors of the mice were excised and at room temperature were frozen in liquid nitrogen or fixed in $4 \%$ paraformaldehyde for subsequent studies. Approved protocols provided by Nanjing Medical University's Institutional Animal Care 
and Research Advisory Committee were followed for all animal experiments.

\section{Immunohistochemistry}

The tumor masses of both mice and clinical samples were $4 \%$ paraformaldehyde fixed, paraffin embedded at $58{ }^{\circ} \mathrm{C}$ and cut into $4 \mu \mathrm{m}$ sections, followed by staining with anti-DYNLT1 antibodies (1:50 dilution, ab202583, Abcam, USA). Aperio Scan-Scope AT Turbo (Aperio, USA) was used to capture images of the tumors, while image-scope software (Media Cybernetics Inc.) was used to conduct the quantitative analysis.

\section{Statistical analysis}

GraphPad Prism 7.00 Software (USA) and SPSS version 22.0 (SPSS, USA) were used to conduct the statistical analyses. Expression is presented as mean \pm SEM of at least three independent experiments for all results. Oneway analysis of variance (ANOVA) or student's t test was performed to determine statistical differences among two or more groups. Sensitivity, specificity, and area under the curve (AUC), including 95\% confidence interval (CI), were computed with the aid of the constructed receiver-operating characteristic (ROC) curves, using the Youden index (J) [25] to calculate the optimum cut-off values. The survival analysis included log-rank tests and Kaplan-Meier analyses. A $P$ value of $<0.05$ was used to indicate a statistically significant result. For all figures: *, $P<0.05 ; * *, P<0.01 ; \& * *, P<$ 0.001 ; and \&\&*** $P<0.0001$.

\section{Results}

\section{MiR-15b-3p is upregulated in GC}

Gene Expression Omnibus (GEO) database microarray data (accession number: GSE86226) were analyzed and the top 61 highly expressed miRNAs (fold change $>1.5$, FDR $<0.01$ ), in comparison with 3 pooled peripheral serum samples from $30 \mathrm{GC}$ patients and 1 pooled sample from 10 controls (Fig. 1a). $281 \mathrm{miR}$ NAs with highly significant expression were identified after the same criteria (fold change $>1.5$, FDR $<0.01$ ) for GC tissues was applied to the TCGA database (Fig. 1b). 29 miRNAs were found to fall into the intersection between the two sets of data (Fig. 1c). Among them, miR-15b-3p was the most prominent in the tumor tissues of $108 \mathrm{GC}$ patients (Additional file 1: Figure S1a-l and Fig. 1d), which is consistent with the expression trend in the TCGA database (Fig. 1e). Table 1 shows the baseline characteristics of the 108 GC patients. Next, significantly higher miR-15b-3p levels were found in GC serum, compared with that of normal serum using qRT-PCR assay ( $n=30$, Fig. 1f). In addition, compared with the GES-1 cell line (Fig. 1g), distinctively elevated expression of miR-15b-
$3 p$ was found in the moderately differentiated adenocarcinoma SGC-7901 cell line and the poorly differentiated adenocarcinoma BGC-823 cell line. Considering the significantly higher miR-15b-3p expression in BGC-823 cells, above that of SGC-7901 cells, we hypothesized that the miR-15b-3p expression is higher in GC cell lines with high malignancy. Collectively, these results show that GC development may involve miR-15b-3p. Hence, we focused on the functional role of miR-15b-3p.

\section{MiR-15b-3p overexpression enhances GC cell proliferation, invasion, migration and inhibits apoptosis} In order to determine whether miR-15b-3p plays a role in GC progression, we first investigated its effect on GC cell proliferation. Additional file 2 Figure S2 shows miR-15b-3p expression after transfection into SGC-7901 and BGC-823 cells. Results of the colony formation, CCK-8 and 5-ethynyl-2'-deoxy-uridine (EdU) assays reveal that in comparison with the respective control groups, treatment with miR-15b-3p mimics accelerate the proliferation of SGC-7901 and BGC-823 cells, while the miR-15b-3p inhibitor significantly inhibits their proliferation (Fig. 2a-c). Figure 2d shows that compared with that of the control group, the invasion and migration rates of the miR-15b-3p mimics-transfected SGC-7901 and BGC-823 cells were significantly higher, whereas the miR-15b-3p inhibitor alone transfected cells could only migrate or invade a short distance. TUNEL assay and flow cytometry analysis were used to explore whether the regulation of apoptosis is a potential factor for miR-15b-3p-induced cell growth progression. Thus, the apoptotic percentage of miR-15b-3p-silenced GC cells were found to be obviously elevated, and the cells overexpressing miR-15b-3p were found to show lower apoptosis levels (Fig. 2e and f). In addition, apoptosis-related protein expression levels were ascertained using western blotting analysis, as shown in Fig. 2g. Significant upregulation of the anti-apoptotic protein, BCL-2, expression was detected in the miR-15b-3p mimics group, which is contrary to that of BAX, Cleaved caspase- 9 and Cleaved caspase- 3 levels. The above mentioned changes were found to be opposite to the changes seen in the miR-15b-3p inhibition group. Accordingly, we speculate that miR-15b-3p functions as an oncogene in GC.

\section{MiR-15b-3p directly targets DYNLT1}

miRNAs play a key role as negative gene expression regulators at post-transcription level by fusing target mRNA complementary 3'UTR sequences $[13,16]$. In order to explore miR-15b-3p regulation at mRNA level, prediction of potential miR-15b-3p target genes 


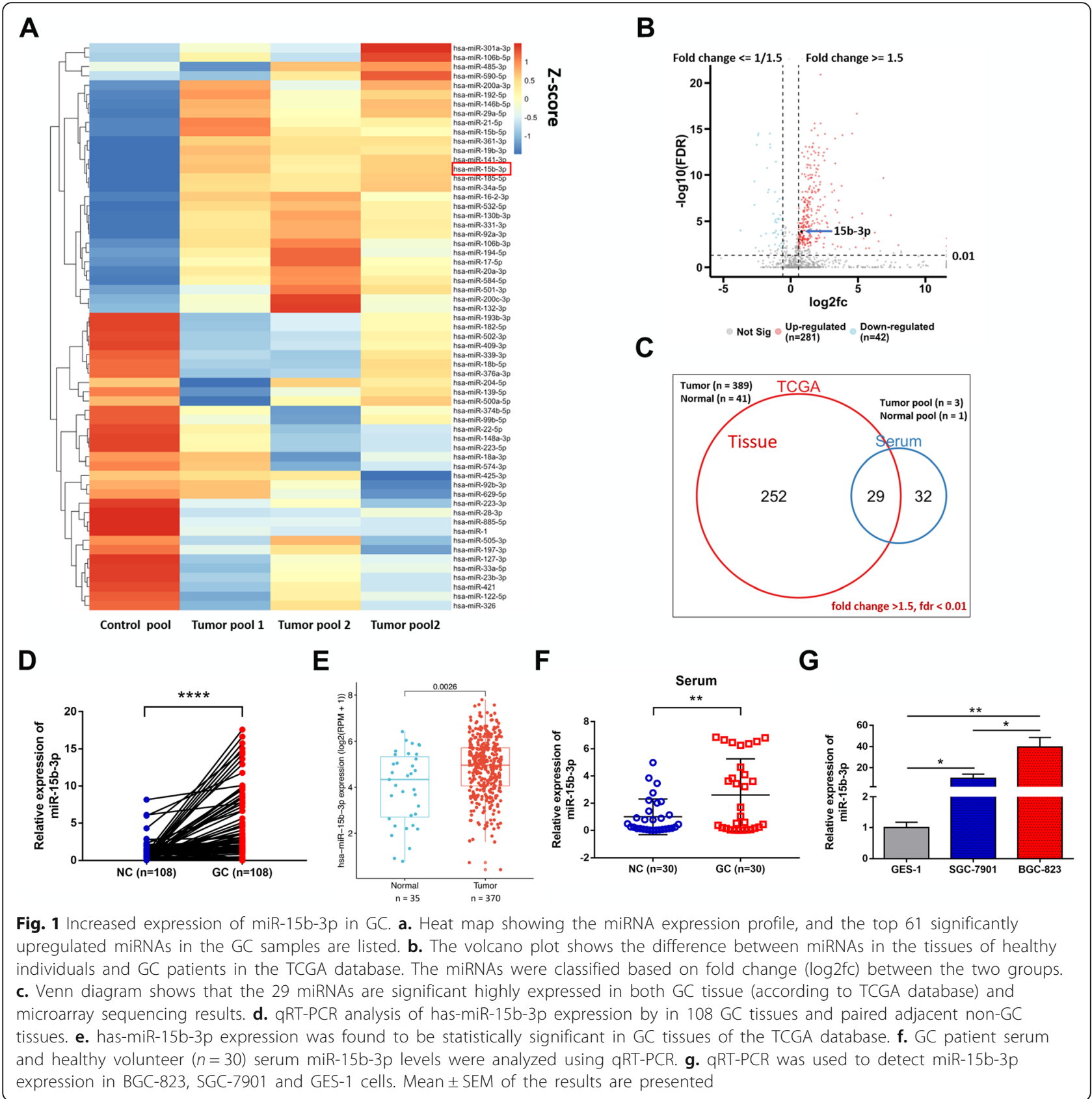

was done by simultaneously using four bioinformatics tools (miRDB, RNA22, TarBase and TargetScan) (Fig. 3a). A significant decrease in DYNLT1 at mRNA level was found in GC tissues, as shown by qRT-PCR assays (Additional file 3: Figure S3a-c and Fig. 3b). A similar trend was seen with DYNLT1 expression in TCGA database GC tissues and normal tissues (Fig. 3c). Determination of DYNLT1 expression was done using western blotting and immunohistochemistry (IHC) analyses. As predicted, the results were similar, indicating that in GC tissues, DYNLT1 is downregulated, compared with matched normal tissues $(n=30$, Fig. 3d-f). The results of the qRT-PCR analysis performed on 108 paired GC tumor tissues $\left(R^{2}=0.3655, P<0.0001\right)$, SGC-7901 cells $\left(R^{2}=0.7726\right.$, $P=0.0008)$ and BGC-823 cells $\left(R^{2}=0.8703, P<0.0001\right)$ found a negative correlation between the expressions of miR-15b-3p and DYNLT1 (Fig. 3g and Additional file 4: Figure S4). In addition, miR-15b-3p was confirmed to downregulate DYNLT1 expression in BGC-823 and SGC-7901 cells at both mRNA, as well as protein level, while DYNLT1 expression upregulation could 
Table 1 Clinicopathological features of 108 non-GC and 108 GC patients

\begin{tabular}{|c|c|c|c|}
\hline Variables & $\mathrm{NC}=108$ & $\mathrm{GC}=108$ & $P$ value \\
\hline Age, years & $60.64 \pm 1.43$ & $62.54 \pm 0.91$ & 0.260 \\
\hline Gender & & & 1.000 \\
\hline Male & $71(65.7 \%)$ & $71(65.7 \%)$ & \\
\hline Female & $37(34.3 \%)$ & $37(34.3 \%)$ & \\
\hline Smoking & & & $0.002^{*}$ \\
\hline Yes & $17(15.7 \%)$ & $37(34.3 \%)$ & \\
\hline No & $91(84.3 \%)$ & $71(65.7 \%)$ & \\
\hline Alcohol abuse & & & $0.012^{*}$ \\
\hline Yes & 12(11.1\%) & $26(24.1 \%)$ & \\
\hline No & 96(88.9\%) & $82(75.9 \%)$ & \\
\hline Family history of cancer & & & $0.000^{*}$ \\
\hline Yes & $2(1.9 \%)$ & 19(17.6\%) & \\
\hline No & 106(98.1\%) & $89(82.4 \%)$ & \\
\hline Hypertension & & & 0.317 \\
\hline Yes & $41(38.0 \%)$ & $34(31.5 \%)$ & \\
\hline No & $67(62.0 \%)$ & $74(68.5 \%)$ & \\
\hline Diabetes mellitus & & & 0.621 \\
\hline Yes & $25(23.1 \%)$ & $22(20.4 \%)$ & \\
\hline No & $83(76.9 \%)$ & $86(79.6 \%)$ & \\
\hline Heart disease & & & 1.181 \\
\hline Yes & $10(9.3 \%)$ & $5(4.6 \%)$ & \\
\hline No & $98(90.7 \%)$ & 103(95.4\%) & \\
\hline Pulmonary disease & & & 0.269 \\
\hline Yes & $5(4.6 \%)$ & $9(8.3 \%)$ & \\
\hline No & 103(95.4\%) & $99(91.7 \%)$ & \\
\hline History of taking NSAIDs & & & 0.249 \\
\hline Yes & $2(1.9 \%)$ & $5(4.6 \%)$ & \\
\hline No & $106(98.1 \%)$ & 103(95.4\%) & \\
\hline
\end{tabular}

${ }^{*} P<0.05$

be achieved by silencing miR-15b-3p (Fig. 3h and i). The direct interaction between miR-15b-3p and DYNLT1 was demonstrated using either a wild-type (WT) or mutant 3'-UTR DYNLT1 mRNA containing a luciferase reporter plasmid. As shown in Fig. 3j, miR-15b-3p harbors a complementary binding sequence of DYNLT1. Subsequently, miR-15b-3p overexpressing BGC-823 and SGC-7901 cells showed a significant decrease in luciferase activity, whereas the luciferase activity was obviously enhanced by miR15b-3p inhibition (Fig. 3k). However, the loss of binding sites eliminated the miR-15b-3p inhibitory effect on luciferase activity, as shown in Fig. 3k. Thus, DYNLT1 was confirmed as a direct downstream miR15b-3p target.
Serum exo-miR-15b-3p as a potential GC diagnosis and prognosis biomarker

Considering that exosomes are highly stable disease biomarkers, exo-miRNAs may be potential GC diagnostic or prognostic biomarkers that are more accurate and stable than miRNAs [26-28]. In order to explore whether exo-miR-15b-3p performs the above functions, we first extracted and purified exosomes from the conditioned media of three cell lines (BGC823, SGC-7901 and GES-1) and the serum of GC patients and non-GC volunteers $(n=108$, patients and volunteers as listed in Table 1). Exosome quantity and number, as well as their cup-shaped morphology were determined through TEM analysis and Nano Sight particle tracking analysis (Fig. 4a and b). Moreover, the exosomal markers, TSG101, CD63 and CD9, were identified using western blotting analysis, further confirming that exosomes were the particles that were isolated (Fig. 4c). exo-miR-15b-3p was found to be enriched in the CM of SGC-7901 cells, and in particular, BGC-823 cells, rather than GES-1 cells, as shown by the qRT-PCR assay (Fig. 4d). Similarly, miR-15b-3p expression in the $108 \mathrm{GC}$ patient serum exosomes was found to be significantly higher, compared with that of corresponding non-GC controls (Fig. 4e). exo-miR-15b-3p diagnostic efficacy for GC was determined using the ROC curve. The results show that the AUC of 0.820 (95\%CI, 0.763-0.876), with a specificity of $80.6 \%$ and a sensitivity of $74.1 \%$ was obtained for exo-miR-15b-3p, as shown in Fig. $4 f$. The diagnostic effect of serum exo-miR-15b-3p was found to be better than that of miR-15b-3p in tissues $(\mathrm{AUC}=0.674[0.600-0.748])$ and serum $(\mathrm{AUC}=0.642$ [0.499-0.786], Additional file 5: Figure S5a and b). The correlation between clinicopathological features and serum exo-miR-15b-3p levels of expression were determined by dividing patients into a highexpression group and a low-expression group, with 54 patients assigned to each, based on the median miR15b-3p expression level. A statistically significant correlation was observed between high serum exo-miR$15 \mathrm{~b}-3 \mathrm{p}$ expression and alcohol abuse, tumor size $(\geq 3.5 \mathrm{~cm}$ in diameter), poorly differentiated histological type, TNM stage (III and IV) and lymph vascular invasion (Table 2). Furthermore, Kaplan-Meier analysis was performed to judge whether serum exomiR-15b-3p expression is correlated with GC patient cancer-specific survival. As shown in Fig. 4g, poor overall survival $(P=0.019)$ can be accurately predicted by high exo-miR-15b-3p expression levels. These results indicate that serum-secreted exo-miR-15b-3p can function as a sensitive and specific predictive and prognostic liquid biomarker for GC and may be related with the malignant transformation of GC. 


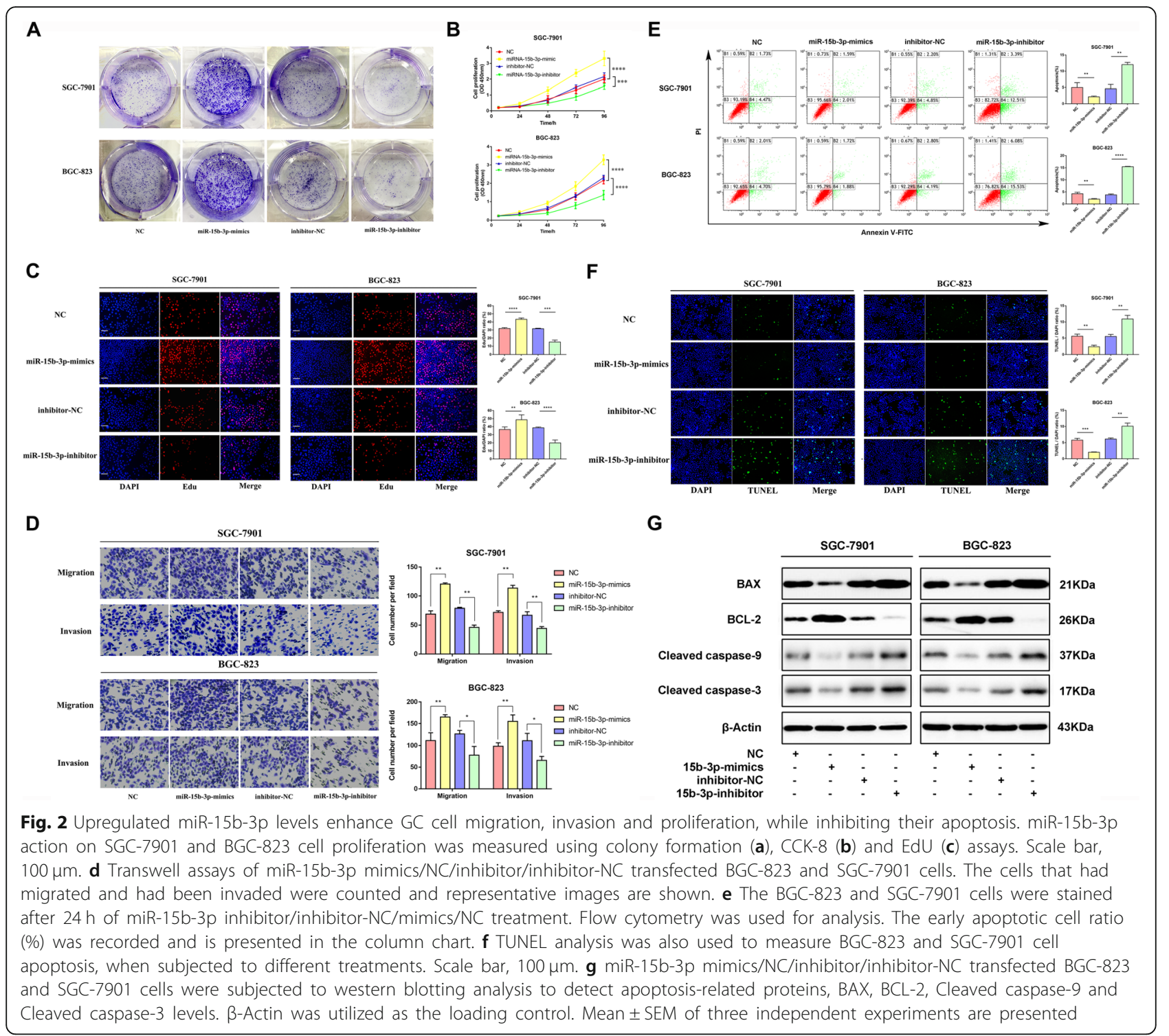

Transfer of miR-15b-3p from BGC-823 cell-derived exosomes to recipient cells

Since miR-15b-3p expression of BGC-823 cells (poorly differentiated adenocarcinoma) is higher than that of SGC-7901 and GES-1 cells, we hypothesized that exosomes can mediate a novel mechanism of cell-to-cell communication in GC, by transmitting miR-15b-3p between cells of varying degrees of differentiation and malignancy, and then take part in the malignant transformation of GC. In order to confirm our assumption and the manner of miR-15b-3p intercellular delivery, we performed co-culture experiments to determine if exosomes and their contents could be internalized by target cells. First, $50 \mathrm{mg}$ of BGC-823 cell derived PKH26-labeled exosomes were incubated with $5 \times 10^{5}$ GES-1 or SGC-7901 cells, and the uptake of exosomes was observed after co-culture for $0,6,12$ and $24 \mathrm{~h}$. It was found that in a timedependent manner, GES-1 and SGC-7901 cells gradually engulfed the exosomes (Fig. 5a). After $24 \mathrm{~h}$ of co-cultivation, many exosomes were found to have entered recipient cells and accumulated around the nucleus (Fig. 5a). Moreover, in order to visualize the exosome-mediated intercellular miRNA transfer, after confirming that GFP-Lv-CD63 had been successfully transfected into BGC-823 cells (Additional file 6: Figure S6a), the fluorescence labeled miR-15b-3p mimics (Cy3-miR-15b-3p mimics) was transiently transfected into BGC-823 cells (Additional file 6: Figure S6b) and then, the medium was refreshed 


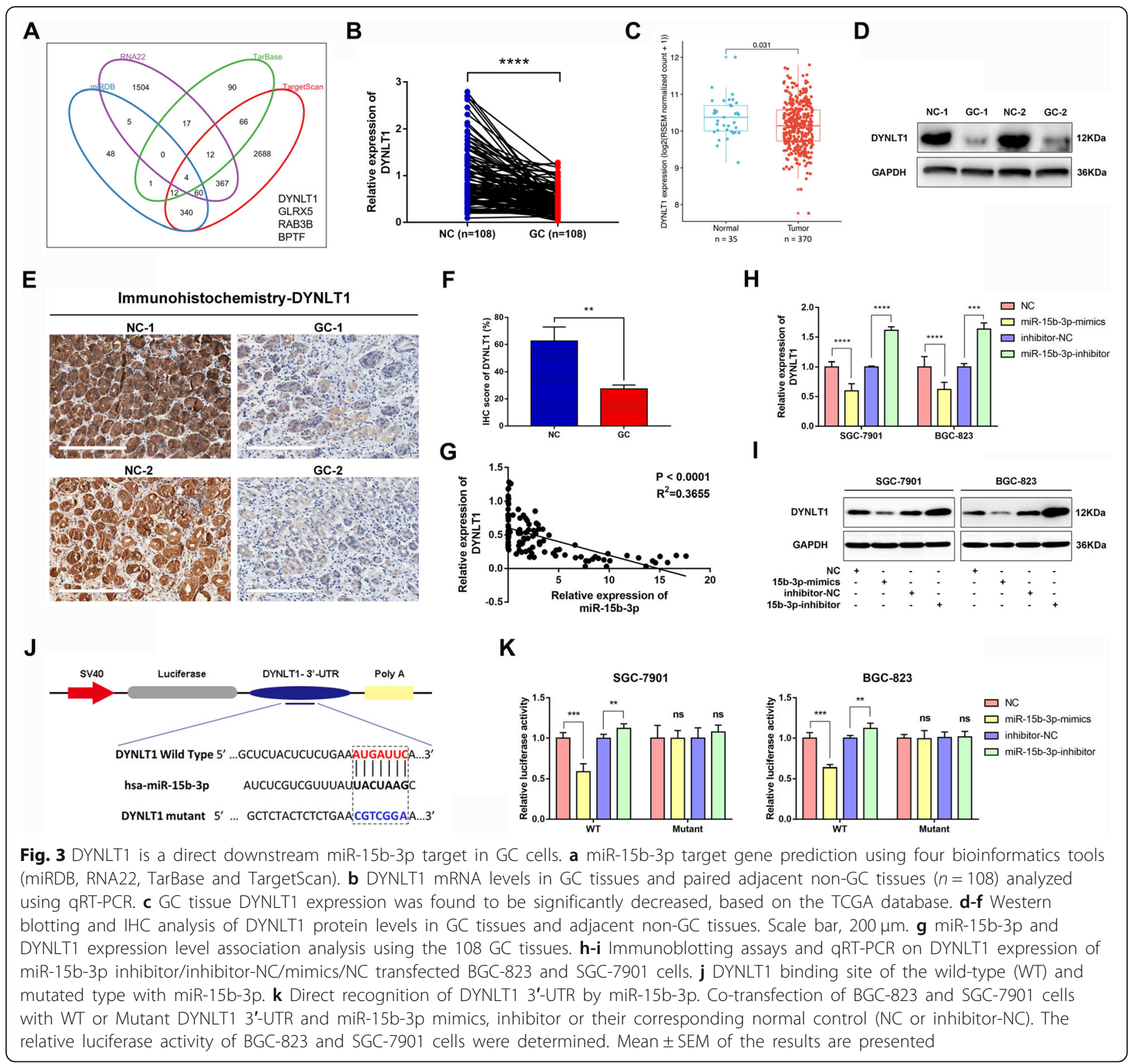

(Additional file 6: Figure S6c). Next, exosomes in the $\mathrm{CM}$ of transfected BGC-823 cells were further isolated and added to the untreated GES-1 and SGC7901 cells for $24 \mathrm{~h}$. The apparent green and red fluorescence seen in Fig. 5b confirms the successful shuttling of Cy3-miR-15b-3p mimics through exosomes into recipient cells. Moreover, Cy3-miR-15b$3 \mathrm{p}$ mimics and CD63-labeled exosomes were found to be co-localized in the cytoplasm (Fig. 5b). In addition, the qRT-PCR assay results show that oligonucleotide sequences (miR-15b-3p mimics/NC/inhibitor/inhibitor-NC) can be taken-up by exosomes and transported into the extracellular medium, where recipient cell uptake regulates $\mathrm{miR}-15 \mathrm{~b}-3 \mathrm{p}$ expression (Fig. 5c).

\section{Intercellular transfer of miR-15b-3p by exosomes promote malignant transformation in vitro}

For further investigating BGC-823 cell-derived exo-miR15b-3p function in recipient cells, we isolated exosomes from the CM of miR-15b-3p inhibitor/inhibitor-NC $/$ mimics/NC transfected BGC-823 cells. Next, $50 \mathrm{mg}$ of the purified exosomes or PBS was co-cultured for $24 \mathrm{~h}$ with $5 \times 10^{5}$ GES-1 or SGC-7901 cells. As expected, when exo-miR-15b-3p mimics were incubated with either SGC-7901 or GES-1 cell lines, increased cell 


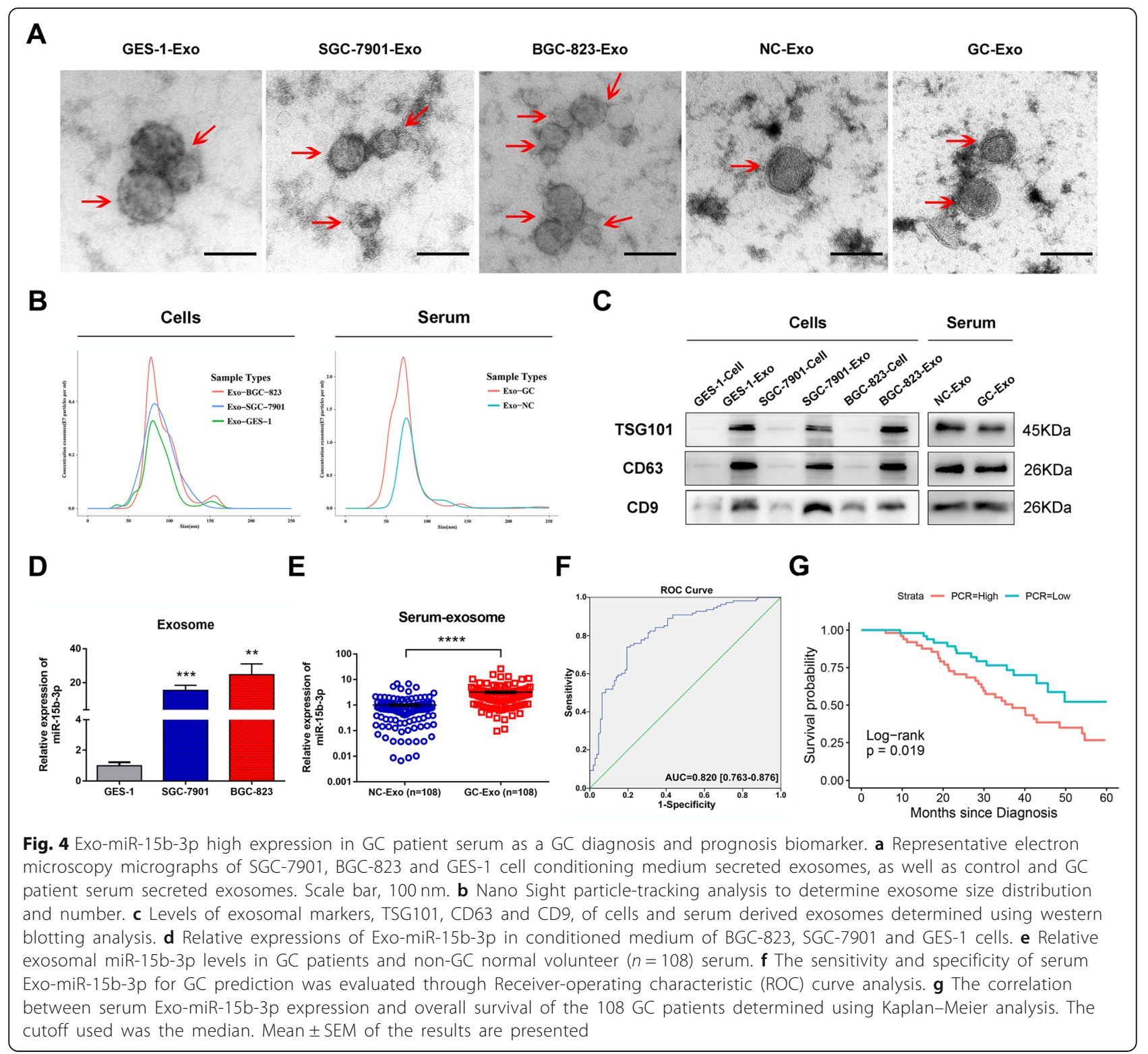

proliferation (tested using colony formation, CCK-8 and EdU assays) (Fig. 6a-c), cell invasion and migration (tested using Transwell chamber migration assay) (Fig. 6d) were observed. In contrast, significant repression of these biological functions were found in cells cocultured with exosomes, in which miR-15b-3p was knocked down (Fig. 6a-d). However, recipient cells treated with control exosomes (Exo-NC and Exoinhibitor-NC) showed greater proliferation, migration and invasion capacities than those treated with PBS (Fig. 6a-d). Furthermore, we found that the apoptosis of GES-1 and SGC-7901 cells treated with exosomes carrying miR-15b-3p mimics was significantly reduced, while knockdown of exo-miR-15b-3p reversed the apoptosis of these cells (Fig. 6e-g). At the protein level, the expression of DYNLT1 and BAX were found to be inhibited in GES-1 and SGC-7901 cells treated with exo-miR-15b-3p mimics, compared with Exo-NC and PBS groups. Conversely, transfection with exosomes containing a miR-15b-3p inhibitor had an opposite effect on their expression (Fig. 6g). In addition, anti-apoptotic protein BCL-2 levels increased in GES-1 and SGC-7901 cells coincubated with exosomes packed with miR-15b-3p mimics and decreased in cells treated with the exo-miR15b-3p inhibitor (Fig. 6g). It is known that DYNLT1 is involved in the regulation of apoptosis [29, 30]. In order to further explore its mechanism of action, we analyzed levels of major proteins in the Caspase-3 classical 
Table 2 Association of miR-15b-3p Expression in GC with Different Clinicopathological Features

\begin{tabular}{|c|c|c|c|}
\hline \multirow[t]{2}{*}{ Variables } & \multicolumn{2}{|c|}{ Exo-miR-15b-3p expression } & \multirow[t]{2}{*}{$P$-value } \\
\hline & $\operatorname{Low}(n=54)$ & $\operatorname{High}(n=54)$ & \\
\hline Age, years & & & 0.425 \\
\hline$<60$ & $22(40.7 \%)$ & 18(33.3\%) & \\
\hline$\geq 60$ & $32(59.3 \%)$ & $36(66.7 \%)$ & \\
\hline Gender & & & 0.661 \\
\hline Male & $41(75.9 \%)$ & $39(72.2 \%)$ & \\
\hline Female & $13(24.1 \%)$ & $15(27.8 \%)$ & \\
\hline Smoking & & & 0.311 \\
\hline Yes & $16(29.6 \%)$ & $21(38.9 \%)$ & \\
\hline No & $38(70.4 \%)$ & $33(61.1 \%)$ & \\
\hline Alcohol abuse & & & $0.024^{*}$ \\
\hline Yes & $8(14.8 \%)$ & 18(33.3\%) & \\
\hline No & $46(85.2 \%)$ & $36(66.7 \%)$ & \\
\hline Family history of cancer & & & 0.206 \\
\hline Yes & $7(13.0 \%)$ & $12(22.2 \%)$ & \\
\hline No & $47(87.0 \%)$ & $42(77.8 \%)$ & \\
\hline Size, $\mathrm{cm}$ & & & $0.020^{*}$ \\
\hline$<3.5$ & $30(55.6 \%)$ & 18(33.3\%) & \\
\hline$\geq 3.5$ & $24(44.4 \%)$ & $36(66.7 \%)$ & \\
\hline Location & & & 0.267 \\
\hline Cardia & $16(29.6 \%)$ & $11(20.4 \%)$ & \\
\hline Non-cardia & $38(70.4 \%)$ & $43(79.6 \%)$ & \\
\hline Lauren's classification & & & 0.101 \\
\hline Intestinal type & $22(40.7 \%)$ & $14(25.9 \%)$ & \\
\hline Diffuse type & $20(37.0 \%)$ & $31(57.4 \%)$ & \\
\hline Mixed type & $12(22.2 \%)$ & $9(16.7 \%)$ & \\
\hline Histological grade & & & $0.011^{*}$ \\
\hline Well differentiated & $22(40.7 \%)$ & 10(18.5\%) & \\
\hline Poor differentiated & $32(59.3 \%)$ & $44(81.5 \%)$ & \\
\hline Invasion depth & & & 0.176 \\
\hline $\mathrm{T} 1 / 2$ & $28(51.9 \%)$ & $21(38.9 \%)$ & \\
\hline $\mathrm{T} 3 / 4$ & $26(48.1 \%)$ & $33(61.1 \%)$ & \\
\hline Tumor stage & & & $0.002^{*}$ \\
\hline $1, \|$ & $38(70.4 \%)$ & $22(40.7 \%)$ & \\
\hline $\mathrm{III}, \mathrm{IV}$ & $16(29.6 \%)$ & $32(59.3 \%)$ & \\
\hline Lymphovascular invasion & & & $0.001^{*}$ \\
\hline Negative & $37(68.5 \%)$ & $20(37.0 \%)$ & \\
\hline Positive & $17(31.5 \%)$ & $34(63.0 \%)$ & \\
\hline
\end{tabular}

${ }^{*} P<0.05$

apoptosis signaling pathway and found increased cleavage of Caspase- 9 and Caspase-3 in the high DYNLT1 expression group, which was inhibited in the low DYNLT1 expression group (Fig. 6g). Collectively, these results indicate that BGC-823 cell-derived exo-miR-15b-3p is effectively involved in the malignant transformation of recipient cells.

\section{Exo-miR-15b-3p/DYNLT1/Caspase-3/Caspase-9 enhances tumorigenicity in vivo}

Subsequently, the in vitro changes seen in GES-1 and $\mathrm{GC}$ cells in the presence of exo-miR-15b-3p were confirmed in vivo. The nude mice were subcutaneously injected with SGC-7901 cells, following BGC823 cell-derived Exo-Lv-NC, Exo-Lv-miR-15b-3p, ExoLv-inNC and Exo-Lv-inhibitor or PBS pre-incubation. The stable transfection efficiency of the luciferaselabelled lentivirus into BGC-823 cells and the miR15b-3p expression of exosomes derived from cells of different treatment groups are shown in Fig. 7a. We observed that tumor growth increased significantly in mice receiving exosomes enriched with miR-15b-3p, compared with those injected with PBS or exosomes containing Lv-NC (Fig. $7 \mathrm{~b}$ and $\mathrm{c}$ ), at the same time luciferase intensities were also detected (Fig. 7d). However, visibly smaller tumors were formed in the Exo-Lv-inhibitor group (Fig. 7b-d). Next, tumor tissues harvested for TUNEL staining were found to show a decrease in GC cell apoptotic rate, after treatment with Exo-Lv-miR-15b-3p, compared with those treated with Exo-Lv-NC, whereas the opposite result was detected in the Exo-Lv-inhibitor group (Fig. 7e and $\mathrm{f}$ ). Furthermore, we found the results to be consistent with the in vitro results, indicating that both exosome-delivered $\mathrm{NC}$ and inhibitor-NC significantly repressed cell apoptosis, compared with treatment with PBS alone, suggesting that BGC-823 cell-derived exosomes can inhibit target cell apoptosis (Fig. 7e and f). Compared with the control group, qRT-PCR quantified tumor tissue miR-15b-3p levels were significantly higher in the Exo-Lv-miR-15b-3p group and decreased in the Exo-Lv-inhibitor group, while the results of both qRT-PCR and IHC assays indicate that DYNLT1 expression in tissues is inhibited in the first group and enhanced in the second group (Fig. $7 \mathrm{~g}$ and h). However, as shown in Fig. $7 \mathrm{~g}$ and $\mathrm{h}$, no obvious difference was found in the PBS group. Exo-Lv-miR15b-3p treated tumors with high miR-15b-3p levels tended to express lower protein levels of DYNLT1, BAX, Cleaved caspase- 9 and Cleaved caspase-3, but higher protein levels of BCL-2 (Fig. 7i). Conversely, higher protein levels of DYNLT1, BAX, Cleaved caspase-9 and Cleaved caspase-3, but lower BCL-2 levels were observed in the low miR-15b-3p groups (Exo-Lv-inhibitor treated) (Fig. 7i). Our results suggest that the exo-miR-15b-3p/DYNLT1 axis inhibits apoptosis via modulating the Caspase-3/Caspase-9 


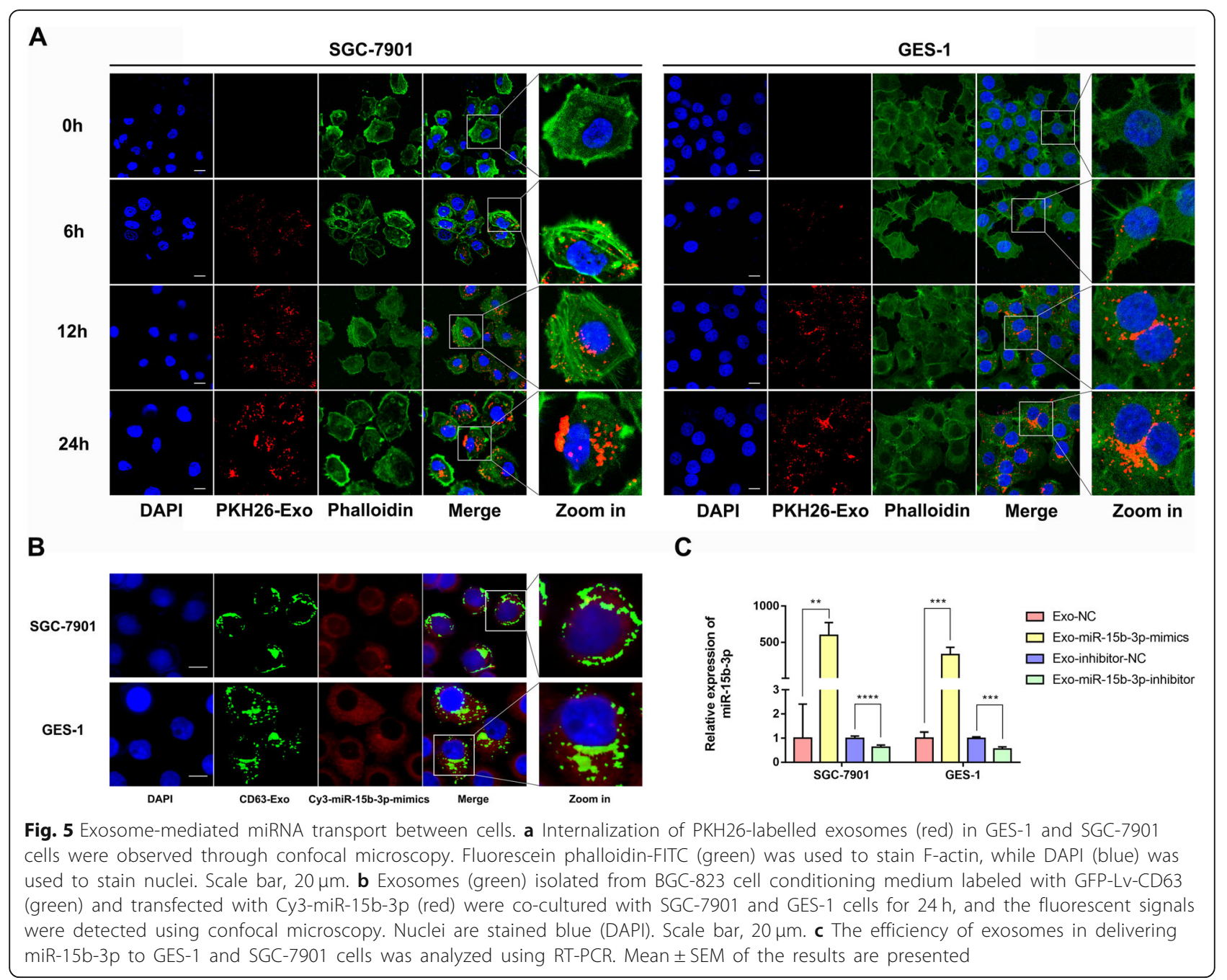

signaling pathway, maintaining high levels of SGC7901 cell proliferation in vivo.

\section{Discussion}

Evidence from previous research has provided the following sequential stages for a human gastric carcinogenesis model: chronic active gastritis, gastric atrophy, intestinal metaplasia, and dysplasia [31]. The development of tumors, including $\mathrm{GC}$, requires continued oncogenic reprogramming to determine the malignant characteristics of cells. Exosomes are potential communicative vectors that act as intercellular mediators, providing dual-role oncosignals in gastric tumorigenesis [32]. Among them, carcinogenic components of GC-derived exosomes can cause the malignant transformation of recipient cells, promoting cell proliferation and migration [33-35]. It has been found that tumor progression and growth can be successfully analyzed by studying exosomes. Currently, exo-miRNAs can regulate different pathological and physiological processes through the inhibition or activation of certain regulatory pathways by shuttling into recipient cells and modifying gene or protein expression, especially for the regulation of GC processes. Thus, serving as circulating biomarkers of $\mathrm{GC}$ and a tool for targeted therapies [8, 13, 32, 36, 37].

As important gene regulators, the miR-15b family is involved in the cell cycle, cellular proliferation and apoptosis, and has been found to be dysfunctional in various diseases [38]. Expression levels of miR-15b-3p have been reported to be significantly upregulated in rs363050 SNAP-25 GG homozygous Alzheimer's disease [39], Microcystin-LR-induced hepatotoxicity [40], myocardial ischemic reperfusion injury [41], coronary artery disease [42], and poor prognosis of hepatocellular carcinoma patients after curative hepatectomy [43]. Therefore, miR-15b-3p expression may be positively correlated with the progression of the disease. 




Moreover, serum miR-15b-3p levels have been reported to constitute a novel biomarker of epicardial fat burden [44], while serum miR-15b has potential as a predictive biomarker of obesity [45]. However, the potential association between the miR-15b family and GC is controversial. miR-15b has been shown to be downregulated in SGC7901/DDP cells [46] and gastric adenoma [47], while Yuan et al. [48] has shown the significant overexpression of miR-15b in GC, which was found by analyzing $1000 \mathrm{GC}$ samples included in four public datasets. In addition, miR-15b-5p impact on invasion, migration and proliferation of GC cells with high miR-15b-5p levels in GC cell lines, tissues and serum samples were confirmed by Zhao et al. [49]. In addition, miR-15b has been repeatedly demonstrated to target important BCL-2 family proteins, including both anti-apoptotic (e.g., Bcl-2) and pro-apoptotic (e.g., Bax) members and regulate the expression of caspases $3,7,8$, or 9 , as well as participate in tumorigenesis and tumor development by enhancing or inhibiting cell activity, proliferation and apoptosis [50-55]. However, in GC, miR-15b-3p expression and function are not clear as yet.

The present study screened 13 miRNAs that may be involved in GC progression from among $29 \mathrm{miR}$ NAs that were upregulated, in both the GSE86226 dataset and TCGA database using qRT-PCR analysis, in which miR-15b-3p was most overexpressed in GC tissues. miR-15b-3p overexpression was subsequently found in GC serum and cell lines for the first time. 


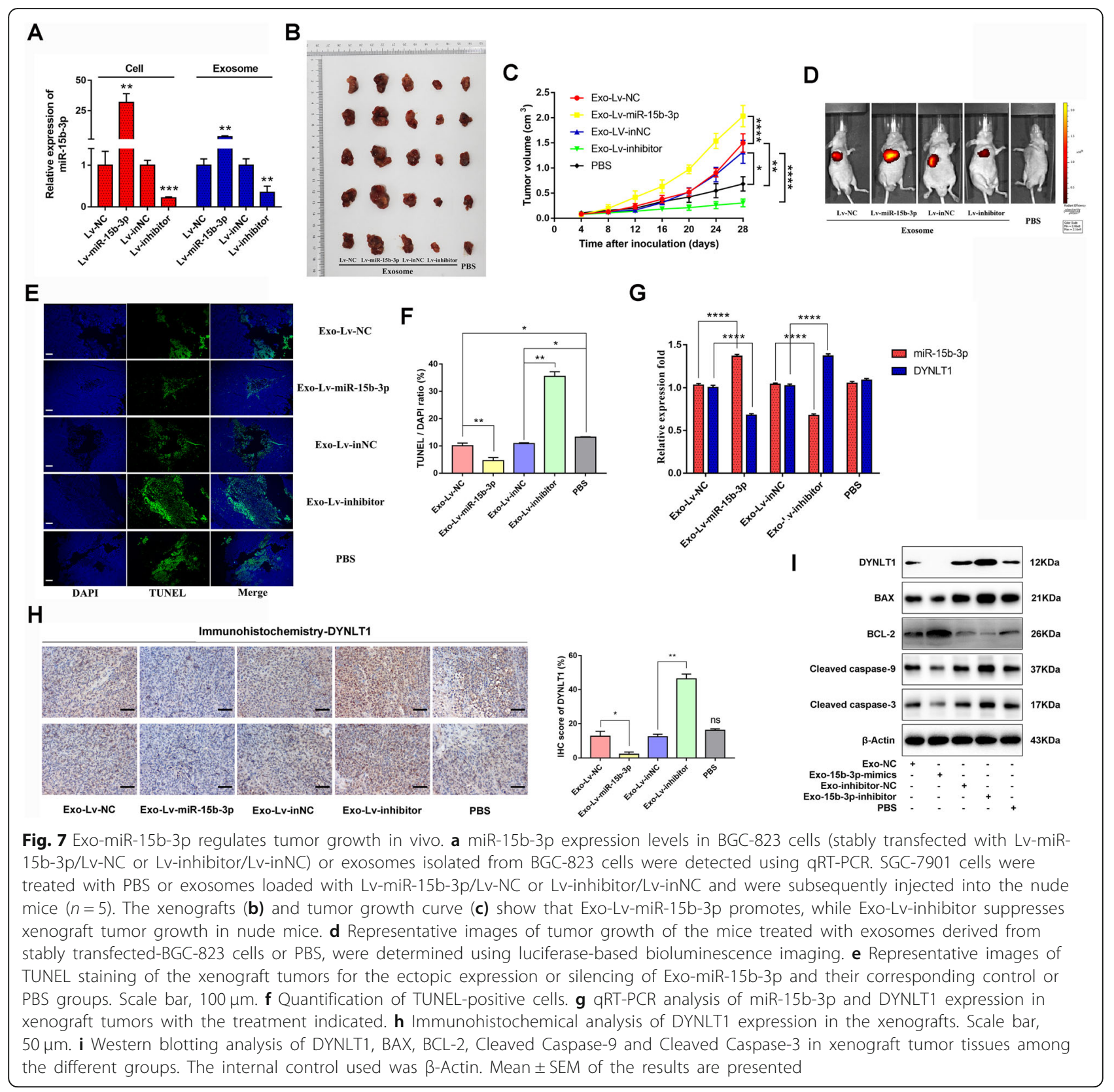

The key regulatory effects of miR-15b-3p on GC cell apoptosis have been confirmed by three different experimental methods. Consistently, we observed that GC cell miR-15b-3p overexpression increases BCL-2 expression, as well as decreases BAX, Cleaved caspase- 9 and Cleaved caspase- 3 expression, whereas miR-15b-3p knockdown reverses this effect. Thus, our results prove for the first time that miR-15b-3p is significantly upregulated in GC and acts as an oncogene for GC.

Moreover, miR-15b-3p was found to function directly by targeting DYNLT1, herein, its official complete name, dynein light chain Tctex-type 1, which is also known as CW-1, TCTEL1 or tctex-1. DYNLT1 encodes a component of the motor complex that transports cellular cargo along microtubules of the cell. Therefore, this gene may be an indispensable host cell protein for transporting material into the nucleus [56]. Meanwhile, the DYNLT1 gene located at $6 \mathrm{q} 25.3$ [57], the long arm of chromosome 6 (6q), has been found to be frequently lost in GC, especially in gastric adenocarcinoma [58-61], and may therefore harbor a tumor suppressor gene [61], which is consistent with the downregulation of DYNLT1 
expression in GC found here. However, the effect of DYNLT1 on the progression of GC remains unclear.

In order to explore whether miRNAs are enriched and stable in the circulatory exosomal system, as previously reported [28], in the CM of GC cells and serum of 108 GC patients, exo-miR-15b-3p was found to be evidently overexpressed and can function as a potential GC diagnosis and poor prognosis biomarker. Moreover, we confirmed for the first time that exo-miR-15-3p is secreted by poorly differentiated adenocarcinoma (BGC-823) cells that can be internalized and absorbed by normal GES-1 gastric mucosa epithelium cells and moderately differentiated adenocarcinoma (SGC-7901) cells, suggesting that miR-15b-3p is probably suitable to be packed into exosomes to maintain its stability and intercellular transfer. A series of functional experiments that were subsequently conducted, demonstrated that exo-miR-15b-3p maintains miR-15b-3p carcinogenesis and is involved in tumorigenesis and GC progression, both in vivo and in vitro. This effect may be achieved by the exo-miR15b-3p-induced downregulation of DYNLT1. Voltagedependent anion channel 1 (VDAC1) is a key component of mitochondria-mediated apoptosis, and exerts a protective effect on anti-apoptotic proteins, including BCL-2 [62, 63]. Combined with the report by Ochiai et al. that DYNLT1 is the target protein of VDAC1 [30], we speculated that DYNLT1 is implicated in apoptosis regulation. In addition, DYNLT1 has previously been considered as an interacting partner of REIC/Dkk-3, inducing apoptosis through its action as a multiple cancer cell line tumor suppressor [29]. In our study, proapoptotic protein, BAX expression was found to be positively correlated with DYNLT1 expression, while the anti-apoptotic protein, BCL-2 expression showed an

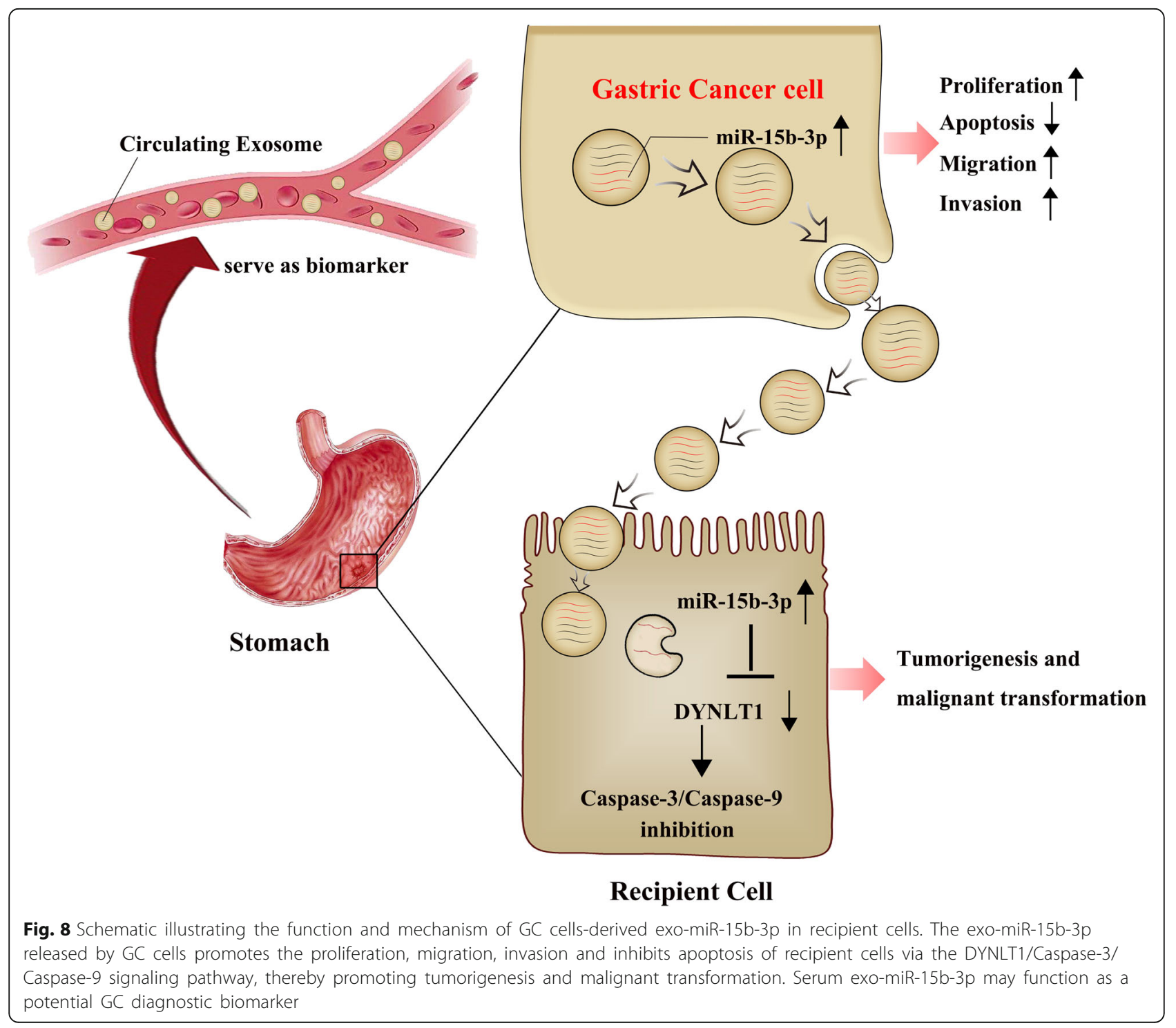


opposite trend to that of DYNLT1, and the Caspase-3/ Caspase-9 pathway was subsequently activated to varying degrees along with changes in exo-miR-15b-3p-induced DYNLT1 expression. However, the precise mechanism by which DYNLT1 modulates the expression of the BCL-2 family of proteins and Cleaved Caspase-3/ Caspase-9 signaling pathway activation are not clear, and we intend to explore these topics in future studies.

\section{Conclusion}

In brief, our findings demonstrate for the first time that exosomes secreted by BGC-823 cells can transfer miR$15 b-3 p$ into recipient cells, promoting tumorigenesis and malignant transformation, as well as inhibiting apoptosis in vivo and in vitro via the DYNLT1/Caspase-3/Caspase9 signaling pathway. Serum exo-miR-15b-3p in humans may function as a potential GC diagnostic and prognostic biomarker, acting as a significant novel GC therapeutic target (Fig. 8).

\section{Supplementary information}

Supplementary information accompanies this paper at https://doi.org/10. 1186/s13046-019-1511-6.

Additional file 1: Figure S1. Expression of miRNAs in 6 pairs of GC tissues and normal tissues. In addition to miR-15b-3p, 12 miRNAs that may play a role in GC cell proliferation and migration were screened out from among 29 potentially differentially expressed miRNAs. In order to evaluate the relative expression levels of miR-192-5p (a), miR-21-5p (b), miR-141-3p (c), miR-15b-5p (d), miR-185-5p (e), miR-532-5p (f), miR-331-3p (g), miR-106b-3p (h), miR-17-5p (i), miR-20a-3p (j), miR-501-3p (k) and miR-200c-3p (I), qRT-PCR assays were performed. The internal control used was U6. Mean \pm SEM of the results are presented.

Additional file 2: Figure S2. $a$. qRT-PCR analysis of miR-15b-3p expression levels in SGC-7901 and BGC-823 cells after oligonucleotide transfection. The internal control was U6. Mean \pm SEM of three independent experiments are presented.

Additional file 3: Figure S3. mRNA expression levels in 10 pairs of GC tissues and normal tissues. qRT-PCR analysis of GLRX5 (a), RAB3B (b) and BPTF (c) relative expression levels between GC tissue and paired adjacent non-GC tissue. The internal control was GAPDH. Mean \pm SEM of the results are presented.

Additional file 4: Figure S4. The correlation between miR-15b-3p and DYNLT1 in vitro. Association analysis of the relationship between miR15b-3p and DYNLT1 expression levels in SGC-7901 cells (a) and BGC-823 cells (b).

Additional file 5: Figure S5. ROC curves of tissue and serum miR-15b-3p in GC vs non-GC control groups. a. ROC curve of tissue miR-15b-3p panel to discriminate GC patients from NCs. $\mathbf{b}$. ROC curves were used to determine the diagnostic efficacy of serum miR-15b-3p for GC. Mean \pm SEM of the results are presented.

Additional file 6: Figure S6. Fluorescence images of BGC-823 cells after transfected. a Confocal microscopy images show that BGC-823 cells were stably transfected with GFP-Lv-CD63 (green). Scale bar, $25 \mu \mathrm{m}$. b. Fluorescence visuals of BGC-823 cells transfected with Cy3-miR-15b-3p mimics (red). Scale bar, $25 \mu \mathrm{m}$. c Red fluorescence was observed under fluorescence microscopy after refreshing the conditioned medium of the BGC-823 cells transfected with Cy3-miR-15b-3p mimics. Scale bar, $25 \mu \mathrm{m}$.

Additional file 7: Table S1. Real-time polymerase chain reaction primers. Table S2. Sequences of miR-15b-3p oligo.

\section{Abbreviations}

BCA: Bicinchoninic acid; DAPI: 4'6-diamidino-2-phenylindole; FITC: Fluorescein isothiocyanate; GAPDH: Glyceraldehyde 3-phosphate dehydrogenase; miR15b-3p: microRNA-15b-3p; qRT-PCR: Reverse transcription quantitative polymerase chain reaction; RPMI: Roswell Park Memorial Institute; SEM: Standard error of the mean; SPSS: Statistical product and service solutions

\section{Acknowledgements}

Not applicable.

\section{Authors' contributions}

WSC and PL designed the study. WSC conducted the experiments, created the figures and wrote the manuscript. YJJ helped extract the exosomes. DYN and ZGX helped review the manuscript. SHM, JDC, LX and CMH helped do analysis and interpretation of data. ZWF and ZGX mainly provided technical and material support. All authors have read and approved the final submitted manuscript.

\section{Funding}

This work was supported by National Nature Science Foundation of China (No. 81970499 and 81770561) and Jiangsu medical leading talent and innovation team (No. CXTDA2017033).

Availability of data and materials

All data generated or analyzed during this study are included either in this article or in the additional files.

Ethics approval and consent to participate

The study was approved by the Ethics Committee of Nanjing Medical University and written informed consent was obtained from all patients.

\section{Consent for publication}

We have obtained consents to publish this paper from all the participants.

\section{Competing interests}

The authors declare that they have no competing interest.

Received: 30 October 2019 Accepted: 17 December 2019 Published online: 10 February 2020

\section{References}

1. Sitarz R, Skierucha M, Mielko J, Offerhaus G, Maciejewski R, Polkowski WP. Gastric cancer: epidemiology, prevention, classification, and treatment. Cancer Manag Res. 2018-01-20;10:239-48.

2. Chen W, Zheng R, Baade PD, Zhang S, Zeng H, Bray F, et al. Cancer statistics in China, 2015. CA Cancer J Clin. 2016:66(2):115-32.

3. Jeddi F, Soozangar N, Sadeghi MR, Somi MH, Shirmohamadi M, EftekharSadat AT, et al. Nrf2 overexpression is associated with P-glycoprotein upregulation in gastric cancer. Biomed Pharmacother. 2018-01-01;97:286-92.

4. Zhou Z, Lin Z, He Y, Pang X, Wang Y, Ponnusamy M, et al. The long noncoding RNA D63785 regulates chemotherapy sensitivity in human gastric Cancer by targeting miR-422a. Mol Ther Nucleic Acids. 2018-09-07; 12:405-19.

5. He Z, Li Z, Zhang X, Yin K, Wang W, Xu Z, et al. MiR-422a regulates cellular metabolism and malignancy by targeting pyruvate dehydrogenase kinase 2 in gastric cancer. Cell Death Dis. 2018;9(5):505.

6. Zhao L, Liu Y, Tong D, Qin Y, Yang J, Xue M, et al. MeCP2 promotes gastric Cancer progression through regulating FOXF1/Wnt5a/beta-catenin and MYOD1/Caspase-3 signaling pathways. EBIOMEDICINE. 2017;16:87-100.

7. Schmittgen TD. Exosomal miRNA Cargo as Mediator of Immune Escape Mechanisms in Neuroblastoma. Cancer Res. 2019;79(7):1293-4.

8. Mori MA, Ludwig RG, Garcia-Martin R, Brandao BB, Kahn CR. Extracellular miRNAs: From Biomarkers to Mediators of Physiology and Disease. Cell Metab. 2019;30(4):656-73.

9. Pegtel DM, Gould SJ. Exosomes. Annu Rev Biochem. 2019-06-20;88:487-514.

10. Gurunathan S, Kang MH, Jeyaraj M, Qasim M, Kim JH. Review of the Isolation, Characterization, Biological Function, and Multifarious Therapeutic Approaches of Exosomes. CELLS-BASEL. 2019:8(4). https://doi.org/10.3390/ cells8040307. 
11. Wortzel I, Dror S, Kenific CM, Lyden D. Exosome-Mediated Metastasis: Communication from a Distance. Dev Cell. 2019:49(3):347-60.

12. Ying W, Riopel M, Bandyopadhyay G, Dong Y, Birmingham A, Seo JB, et al. Adipose Tissue Macrophage-Derived Exosomal miRNAs Can Modulate In Vivo and In Vitro Insulin Sensitivity. CELL. 2017;171(2):372-84.

13. Liu X, Lu Y, Xu Y, Hou S, Huang J, Wang B, et al. Exosomal transfer of miR501 confers doxorubicin resistance and tumorigenesis via targeting of BLID in gastric cancer. Cancer Lett. 2019-09-10;459:122-34.

14. Monaco F, Gaetani S, Alessandrini F, Tagliabracci A, Bracci M, Valentino M, et al. Exosomal transfer of miR-126 promotes the anti-tumour response in malignant mesothelioma: role of miR-126 in cancer-stroma communication. Cancer Lett. 2019-10-28;463:27-36.

15. Fang T, Lv H, Lv G, Li T, Wang C, Han Q, et al. Tumor-derived exosomal miR$1247-3 p$ induces cancer-associated fibroblast activation to foster lung metastasis of liver cancer. Nat Commun. 2018:9(1):191.

16. Yue X, Lan F, Xia T. Hypoxic Glioma Cell-Secreted Exosomal miR-301a Activates Wnt/beta-catenin Signaling and Promotes Radiation Resistance by Targeting TCEAL7. Mol Ther. 2019;27(11):1939-49.

17. Raimondi L, De Luca A, Gallo A, Costa V, Russelli G, Cuscino N, et al. Osteosarcoma cell-derived exosomes affect tumor microenvironment by specific packaging of microRNAs. CARCINOGENESIS. 2019.https://doi.org/10. 1093/carcin/bgz130.

18. Wolf T, Baier SR, Zempleni J. The Intestinal Transport of Bovine Milk Exosomes Is Mediated by Endocytosis in Human Colon Carcinoma Caco-2 Cells and Rat Small Intestinal IEC-6 Cells. J Nutr. 2015;145(10): 2201-6.

19. Lasser C, Eldh M, Lotvall J. Isolation and characterization of RNA-containing exosomes. J Vis Exp. 2012;9(59):e3037.

20. Zhang H, Deng T, Liu R, Bai M, Zhou L, Wang X, et al. Exosome-delivered EGFR regulates liver microenvironment to promote gastric cancer liver metastasis. Nat Commun. 2017;8:15016.

21. Zhang $X$, Wang S, Wang H, Cao J, Huang X, Chen Z, et al. Circular RNA circNRIP1 acts as a microRNA-149-5p sponge to promote gastric cancer progression via the AKT1/mTOR pathway. Mol Cancer. 2019;18(1):20.

22. Du X, Zhang L, Li X, Pan Z, Liu H, Li Q. TGF-beta signaling controls FSHR signaling-reduced ovarian granulosa cell apoptosis through the SMAD4/ miR-143 axis. Cell Death Dis. 2016;7(11):e2476.

23. Hao M, Hou S, Xue L, Yuan H, Zhu L, Wang C, et al. Further Developments of the Phenyl-Pyrrolyl Pentane Series of Nonsteroidal Vitamin D Receptor Modulators as Anticancer Agents. J Med Chem. 2018;61 (7):3059-75.

24. Tao $Z H$, Wan $J$, Zeng $L Y$, Xie $L$, Sun $H C$, Qin $L X$, et al. miR-612 suppresses the invasive-metastatic cascade in hepatocellular carcinoma. J Exp Med. 2013;210(4):789-803.

25. YOUDEN WJ. Index for rating diagnostic tests. CANCER-AM CANCER SOC. 1950;3(1):32-5.

26. Huang Z, Zhu D, Wu L, He M, Zhou X, Zhang L, et al. Six Serum-Based miRNAs as Potential Diagnostic Biomarkers for Gastric Cancer. Cancer Epidemiol Biomark Prev. 2017;26(2):188-96.

27. Kumata $Y$, linuma $H$, Suzuki $Y$, Tsukahara $D$, Midorikawa $H$, lgarashi $Y$, et al. Exosomeencapsulated microRNA23b as a minimally invasive liquid biomarker for the prediction of recurrence and prognosis of gastric cancer patients in each tumor stage. Oncol Rep. 2018;40(1):319-30.

28. Boukouris $\mathrm{S}$, Mathivanan $\mathrm{S}$. Exosomes in bodily fluids are a highly stable resource of disease biomarkers. Proteomics Clin Appl. 2015;9(34):358-67.

29. Ochiai K, Watanabe M, Ueki H, Huang P, Fujii Y, Nasu Y, et al. Tumor suppressor REIC/Dkk-3 interacts with the dynein light chain, Tctex-1. Biochem Biophys Res Commun. 2011;412(2):391-5.

30. Fang YD, XU X, Dang YM, Zhang YM, Zhang JP, Hu JY, et al. MAP 4 mechanism that stabilizes mitochondrial permeability transition in hypoxia: microtubule enhancement and DYNLT1 interaction with VDAC1. PLOS One. 2011;6(12):e28052.

31. Correa P. Human gastric carcinogenesis: a multistep and multifactorial process--First American Cancer Society Award Lecture on Cancer Epidemiology and Prevention. Cancer Res. 1992;52(24):6735-40.

32. Kahroba $\mathrm{H}$, Hejazi MS, Samadi N. Exosomes: from carcinogenesis and metastasis to diagnosis and treatment of gastric cancer. Cell Mol Life Sci. 2019;76(9):1747-58.

33. Wu L, Zhang $X$, Zhang B, Shi $H$, Yuan $X$, Sun $Y$, et al. Exosomes derived from gastric cancer cells activate NF-kappaB pathway in macrophages to promote cancer progression. Tumour Biol. 2016;37(9):12169-80.
34. Qu JL, Qu XJ, Zhao MF, Teng YE, Zhang Y, Hou KZ, et al. Gastric cancer exosomes promote tumour cell proliferation through PI3K/Akt and MAPK ERK activation. Dig Liver Dis. 2009;41(12):875-80.

35. Brinton LT, Sloane HS, Kester M, Kelly KA. Formation and role of exosomes in cancer. Cell Mol Life Sci. 2015;72(4):659-71.

36. Sousa D, Lima RT, Vasconcelos MH. Intercellular Transfer of Cancer Drug Resistance Traits by Extracellular Vesicles. Trends Mol Med. 2015;21(10): 595-608.

37. Rahbarghazi R, Jabbari N, Sani NA, Asghari R, Salimi L, Kalashani SA, et al. Tumor-derived extracellular vesicles: reliable tools for Cancer diagnosis and clinical applications. CELL COMMUN SIGNAL. 2019;17(1):73.

38. Sun W, Lan J, Chen L, Qiu J, Luo Z, Li M, et al. A mutation in porcine premiR-15b alters the biogenesis of MiR-15b\16-1 cluster and strand selection of MiR-15b. PLoS One. 2017;12(5):e178045.

39. Agostini S, Mancuso R, Liuzzo G, Bolognesi E, Costa AS, Bianchi A, et al. Serum miRNAs Expression and SNAP-25 Genotype in Alzheimer's Disease. Front Aging Neurosci. 2019;11:52

40. Yang S, Chen L, Wen C, Zhang X, Feng X, Yang F. MicroRNA expression profiling involved in MC-LR-induced hepatotoxicity using high-throughput sequencing analysis. J Toxicol Environ Health A. 2018;81(5):89-97.

41. Liu K, Ma L, Zhou F, Yang Y, Hu HB, Wang L, et al. Identification of microRNAs related to myocardial ischemic reperfusion injury. J Cell Physiol. 2019;234(7):11380-90.

42. Zhong Z, Zhong W, Zhang Q, Zhang Q, Yu Z, Wu H. Circulating microRNA expression profiling and bioinformatics analysis of patients with coronary artery disease by RNA sequencing. J Clin Lab Anal. 2019;5:e23020.

43. Ji WB, Liu X, Luo Y, Zhang WZ. High expression of miR-15b predicts poor prognosis for hepatocellular carcinoma after curative hepatectomy. Oncol Rep. 2016;36(4):1901-8.

44. de Gonzalo-Calvo D, Vilades D, Martinez-Camblor P, Vea A, Ferrero-Gregor A, Nasarre $L$, et al. Plasma microRNA Profiling Reveals Novel Biomarkers of Epicardial Adipose Tissue: A Multidetector Computed Tomography Study. J CLIN MED. 2019;8(6). https://doi.org/10.3390/jcm8060780.

45. Pescador N, Perez-Barba M, Ibarra JM, Corbaton A, Martinez-Larrad MT, Serrano-Rios M. Serum circulating microRNA profiling for identification of potential type 2 diabetes and obesity biomarkers. PLoS One. 2013;8(10): e77251.

46. Song J, Yin J, Bai Z, Zhang J, Meng H, Cai J, et al. The Profile of Serum microRNAs Predicts Prognosis for Resected Gastric Cancer Patients Receiving Platinum-Based Chemotherapy. Dig Dis Sci. 2017: 62(5):1223-34.

47. Hwang J, Min BH, Jang J, Kang SY, Bae H, Jang SS, et al. MicroRNA Expression Profiles in Gastric Carcinogenesis. Sci Rep. 2018;8(1):14393.

48. Yuan C, Zhang Y, Tu W, Guo Y. Integrated miRNA profiling and bioinformatics analyses reveal upregulated miRNAs in gastric cancer. Oncol Lett. 2019;18(2):1979-88.

49. Zhao C, Li Y, Chen G, Wang F, Shen Z, Zhou R. Overexpression of miR-15b$5 p$ promotes gastric cancer metastasis by regulating PAQR3. Oncol Rep. 2017:38(1):352-8.

50. Xia L, Zhang D, Du R, Pan Y, Zhao L, Sun S, et al. miR-15b and miR-16 modulate multidrug resistance by targeting BCL2 in human gastric cancer cells. Int J Cancer. 2008;123(2):372-9.

51. Guo CJ, Pan Q, Li DG, Sun H, Liu BW. miR-15b and miR-16 are implicated in activation of the rat hepatic stellate cell: An essential role for apoptosis. J Hepatol. 2009:50(4):766-78.

52. Ye EA, Steinle JJ. miR-15b/16 protects primary human retinal microvascular endothelial cells against hyperglycemia-induced increases in tumor necrosis factor alpha and suppressor of cytokine signaling 3. J Neuroinflammation. 2015;12:44.

53. Liu L, Zhang G, Liang Z, Liu X, Li T, Fan J, et al. MicroRNA-15b enhances hypoxia/reoxygenation-induced apoptosis of cardiomyocytes via a mitochondrial apoptotic pathway. APOPTOSIS. 2014;19(1):19-29.

54. An F, Gong B, Wang $H$, Yu D, Zhao G, Lin L, et al. miR-15b and miR-16 regulate TNF mediated hepatocyte apoptosis via BCL2 in acute liver failure. APOPTOSIS. 2012;17(7):702-16.

55. Xiao J, Liu L, Zhong Z, Xiao C, Zhang J. Mangiferin regulates proliferation and apoptosis in glioma cells by induction of microRNA-15b and inhibition of MMP-9 expression. Oncol Rep. 2015;33(6):2815-20.

56. Schneider MA, Spoden GA, Florin L, Lambert C. Identification of the dynein light chains required for human papillomavirus infection. Cell Microbiol. 2011;13(1):32-46. 
57. Watanabe TK, Fujiwara T, Shimizu F, Okuno S, Suzuki M, Takahashi E, et al. Cloning, expression, and mapping of TCTEL1, a putative human homologue of murine Tcte1, to 6q. Cytogenet Cell Genet. 1996;73(1-2):153-6.

58. Li BC, Chan WY, Li CY, Chow C, Ng EK, Chung SC. Allelic loss of chromosome 6q in gastric carcinoma. Diagn Mol Pathol. 2003;12(4):193-200.

59. Stamouli MI, Ferti AD, Panani AD, Raftakis J, Consoli C, Raptis SA, et al. Application of multiplex fluorescence in situ hybridization in the cytogenetic analysis of primary gastric carcinoma. Cancer Genet Cytogenet. 2002;135(1):23-7.

60. Carvalho B, Seruca R, Carneiro F, Buys CH, Kok K. Substantial reduction of the gastric carcinoma critical region at 6q16.3-q23.1. Genes Chromosom Cancer. 1999;26(1):29-34.

61. Carvalho B, van der Veen A, Gartner F, Carneiro F, Seruca R, Buys CH, et al. Allelic gains and losses in distinct regions of chromosome 6 in gastric carcinoma. Cancer Genet Cytogenet. 2001;131(1):54-9.

62. Shoshan-Barmatz V, Keinan N, Abu-Hamad S, Tyomkin D, Aram L. Apoptosis is regulated by the VDAC1 N-terminal region and by VDAC oligomerization: release of cytochrome c, AIF and Smac/Diablo. Biochim Biophys Acta. 2010; 1797(6-7):1281-91.

63. Abu-Hamad S, Arbel N, Calo D, Arzoine L, Israelson A, Keinan N, et al. The VDAC1 N-terminus is essential both for apoptosis and the protective effect of anti-apoptotic proteins. J Cell Sci. 2009;122(Pt 11):1906-16.

\section{Publisher's Note}

Springer Nature remains neutral with regard to jurisdictional claims in published maps and institutional affiliations.

Ready to submit your research? Choose BMC and benefit from:

- fast, convenient online submission

- thorough peer review by experienced researchers in your field

- rapid publication on acceptance

- support for research data, including large and complex data types

- gold Open Access which fosters wider collaboration and increased citations

- maximum visibility for your research: over $100 \mathrm{M}$ website views per year

At $\mathrm{BMC}$, research is always in progress.

Learn more biomedcentral.com/submissions 